\title{
Connections Between Clouds, Radiation, and Midlatitude Dynamics: a Review
}

\author{
Paulo Ceppi ${ }^{1}$ • Dennis L. Hartmann ${ }^{1}$
}

Published online: 23 April 2015

(C) Springer International Publishing AG 2015

\begin{abstract}
We review the effects of dynamical variability on clouds and radiation in observations and models and discuss their implications for cloud feedbacks. Jet shifts produce robust meridional dipoles in upper-level clouds and longwave cloudradiative effect (CRE), but low-level clouds, which do not simply shift with the jet, dominate the shortwave CRE. Because the effect of jet variability on CRE is relatively small, future poleward jet shifts with global warming are only a second-order contribution to the total CRE changes around the midlatitudes, suggesting a dominant role for thermodynamic effects. This implies that constraining the dynamical response is unlikely to reduce the uncertainty in extratropical cloud feedback. However, we argue that uncertainty in the cloud-radiative response does affect the atmospheric circulation response to global warming, by modulating patterns of diabatic forcing. How cloud feedbacks can affect the dynamical response to global warming is an important topic of future research.
\end{abstract}

Keywords Clouds · Radiation · Atmospheric dynamics · Jet streams $\cdot$ Cloud feedbacks $\cdot$ Interannual variability $\cdot$ Trends · Global warming

\section{Introduction}

Clouds are an essential component of the climate system through their effect on shortwave (SW) and longwave (LW)

This article is part of the Topical Collection on Climate Feedbacks

Paulo Ceppi

ceppi@atmos.washington.edu

1 Department of Atmospheric Sciences, University of Washington, Box 351640, Seattle, WA 98195-1640, USA radiative fluxes. With a globally averaged cloud-radiative effect of $-20 \mathrm{~W} \mathrm{~m}^{-2}$, clouds act to strongly cool the planet [1]. With global warming, however, clouds and their radiative effects are expected to change, providing a feedback that is most likely positive but highly uncertain [1-3]. To better understand the processes driving the cloud response, it is useful to distinguish between those related to circulation changes and those that are not; we refer to these as dynamic and thermodynamic processes, respectively [e.g., 4]. The focus of this review will be on the interaction between dynamics and clouds in the midlatitudes, and we will discuss clouds mainly in terms of their radiative effects.

Understanding the linkages between clouds, radiation and large-scale circulation is important for several reasons. First, studying cloud occurrence as a function of the dynamical state in models and observations is useful to assess the performance of cloud parameterization schemes and may reveal the causes of cloud-radiative biases in climate models [5-7]. Furthermore, the cloud-radiative response to dynamical variability is still poorly understood but may have significant regional climate implications, affecting ocean-atmosphere coupling time scales and the persistence of modes of sea surface temperature (SST) variability $[8,9]$. Finally, understanding cloud-radiative responses to atmospheric circulation changes is important in the context of global warming, since most state-of-the-art climate models predict poleward shifts of the midlatitude jets, or equivalently positive trends in the annular mode indices in both hemispheres $[10,11]$.

Our ability to quantify interactions between clouds and dynamics has been hampered by the lack of high-quality measurements of clouds and radiation with sufficient spatial and temporal coverage. As such measurements have become increasingly available in recent years, however, a number of studies have investigated the interactions between clouds and dynamics, allowing our scientific understanding to 
expand rapidly. In this review paper, we assess our understanding of the linkages between midlatitude dynamical variability and cloud-radiative effects, focusing on three questions:

1. How do the dominant modes of dynamical variability affect clouds and radiation?

2. Does the dynamical response to global warming affect cloud feedbacks?

3. Do model biases in dynamics cause biases in clouds and radiation?

These questions are addressed in the next three sections, based on a synthesis of the recent literature. We then discuss some important implications of previous findings and identify open questions for future research, before concluding with a summary of this review.

\section{Effects of Dynamical Modes of Variability on Clouds and Radiation in Midlatitudes}

We begin by reviewing the effects of the dominant modes of dynamical variability on clouds and radiation in the midlatitudes, in the context of natural (unforced) variability. In the extratropics, large-scale dynamical variability is dominated by the annular modes, consisting of meridional shifts of the jets and storm tracks with associated anomalies in vertical motion and precipitation [12-14]. It is tempting to believe that the meridional displacement of synoptic systems should result in similar shifts in cloudiness and cloud-radiative effects (CRE), as suggested by several studies [1,15-18]. Recent research has revealed a more complex picture of the interactions between dynamics and clouds, however. Here we discuss SW and LW CRE anomalies associated with the annular mode in both observations and models.

The relationship between SW CRE and jet latitude in models and observations is summarized in Fig. 1a for the Southern Hemisphere (SH). In satellite observations, the SW CRE response to a $1^{\circ}$ jet shift appears to be relatively weak and noisy in the SH, with regional anomalies of the order of $\pm 3 \mathrm{~W} \mathrm{~m}^{-2}$ or less in December-February ([19], their Fig. 4b), and much smaller in the zonal mean (Fig. 1a, red curve). It does not reflect a simple poleward shift of total cloud fraction. Although jet shifts are associated with clear annular anomalies in high and low cloud amount [17], the relative weakness of the SW CRE response may be due to canceling contributions from high and low clouds ([17], their Fig. 3a). In climate models, Grise and Polvani [19] showed that considerable disagreement exists among models on the jet-SW CRE relationships. Even in models with strong jet-SW CRE coupling, however, the effect of a poleward jet shift on zonal-mean SW CRE appears to be relatively modest, with anomalies generally smaller than $\pm 2 \mathrm{~W} \mathrm{~m}^{-2}$ per degree of jet shift in austral summer (Fig. 1a). The hemispheric-mean SW effect of a poleward jet shift is negligible in the SH in climate models because contributions from the subtropics and midlatitudes tend to cancel each other ([19], their Fig. 3c).

In contrast, the LW response appears more robustly associated with jet shifts $[19,20]$. The observed LW CRE response to northern annular mode (NAM) variability can be understood in terms of the response of upper-level clouds to anomalous vertical motion [20], so that coherent meridional dipoles in cloud incidence and LW CRE occur over the North Atlantic and Europe, with positive cloud incidence and LW CRE anomalies poleward of the jet, and negative anomalies equatorward thereof [20, their Figs. 3 and 4]. Similar observations can be made in the SH (Fig. 1b), where the zonal symmetry of the dominant mode of dynamical variability produces fairly annular LW CRE anomalies, with good agreement between observations and models (Fig. 1b) [19, their Figs. 3a and 4a]. All these results are consistent with the conventional wisdom that mid- to high-level cloudiness robustly increases with both mean upward motion [7 (their Fig. 5c), 21] and vertical velocity variance, the latter measuring storm track activity ([7], their Fig. 7a). Thus, analyses of both models and observations show that upper-level clouds tend to follow meridional shifts of the jets and storm tracks, producing robust meridional dipoles in LW CRE about the midlatitudes.

The fact that the SW CRE response to jet variability is much less robust than the LW response is noteworthy and probably reflects an important role of low-level clouds, whose representation is known to be problematic in climate models especially over the Southern Ocean [22]. It is possible that boundary-layer clouds are not related to free-tropospheric vertical motion anomalies in a simple way [23]. Li et al. [7] found opposite responses of high and low clouds to $500-\mathrm{hPa}$ vertical velocity anomalies in observations of midlatitude regions (their Fig. 5c), which seems to support the results of Grise et al. [17].

Although annular modes and associated jet shifts are the dominant mode of dynamical variability in the midlatitudes, other types of variability may also affect clouds and radiation. Using a storm tracking algorithm, Tselioudis and Rossow [24] demonstrated a clear relationship between midlatitude storm intensity and cloudiness, such that more intense storms produce more cloud and larger SW and LW CRE. This appears consistent with the findings of $\mathrm{Li}$ et al. [7] associating larger vertical velocity variance in midlatitudes with enhanced cloudiness. Variations in storm track intensity have recently been shown to occur naturally in association with a mode of hemispheric-scale dynamical variability, the baroclinic annular mode [BAM; 25, 26], with a dominant period of 20-30 days. The BAM might thus be associated with large-scale variations in cloud and radiation; the magnitude of this possible effect remains 

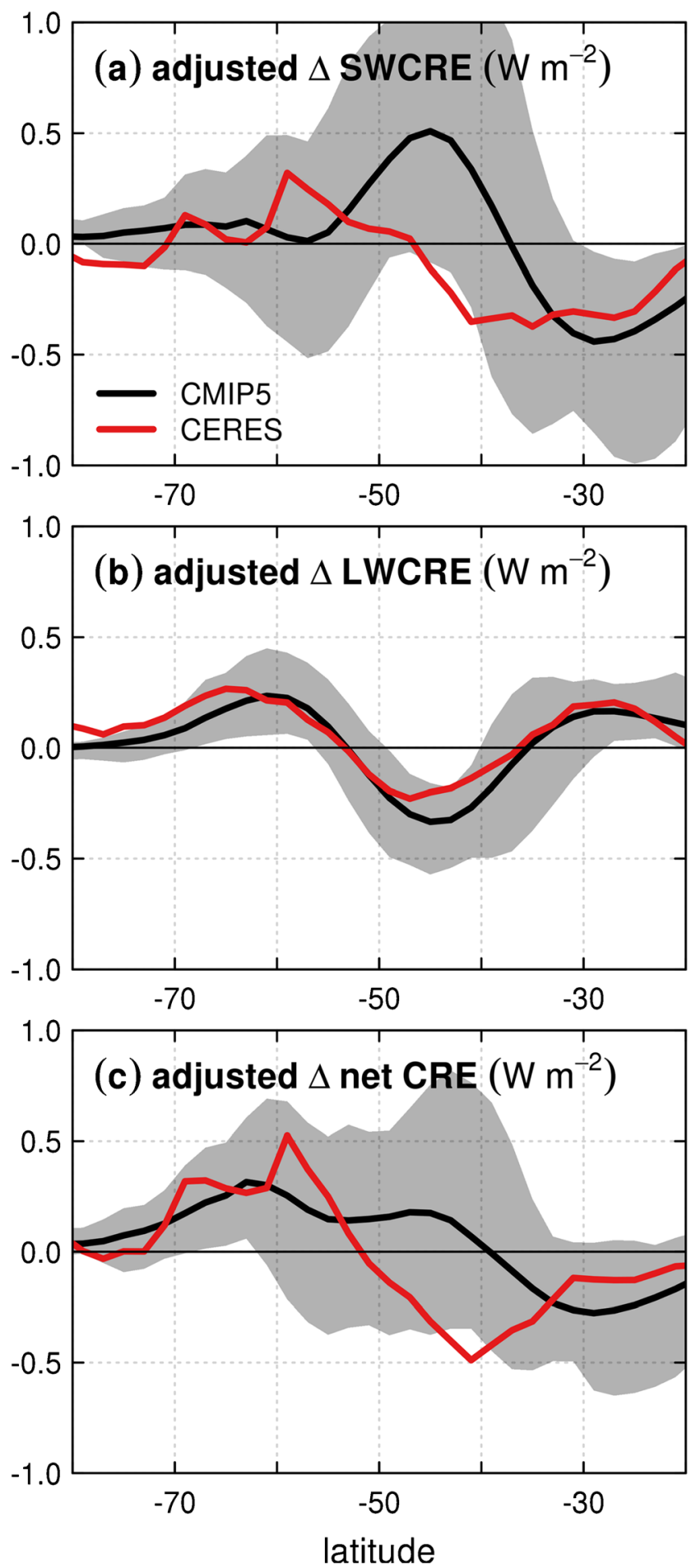

Fig. 1 a-c Annual-mean cloud radiative effect (CRE) response to a $1^{\circ}$ poleward jet shift in the Southern Hemisphere. The black curve is the CMIP5 historical multi-model mean (with $90 \%$ intervals in gray shading), while the red curve is an observational estimate based on CERES-EBAF data (March 2000-February 2014), combined with ERA-Interim 850 -hPa zonal wind. The jet-CRE relationships are obtained by regressing CRE onto monthly mean jet latitude [see also 19, 28]. The CRE responses are adjusted to account for cloud masking effects, as in Soden et al. [2] to be quantified, however, and the dominance of the low cloud effect on shortwave radiation may greatly mute the influence of storminess.

While we describe the SW and LW CRE responses to midlatitude dynamical variability as relatively weak on zonalmean scales, the CRE responses are non-negligible regionally and their possible relevance remains to be studied. Grise and Polvani [19] showed that transient SST anomalies following $\mathrm{CO}_{2}$ quadrupling reflect the jet-CRE relationships in coupled models because the rapid poleward jet shift affects the transient CRE anomalies. However, it is unclear to what extent this result applies to more realistic scenarios with gradual $\mathrm{CO}_{2}$ increase and circulation change. Another possible impact of CRE responses to dynamical variability is on the persistence of modes of atmospheric and oceanic variability, since the cloud-radiative anomalies could act to amplify or dampen temperature variations associated with dynamical variability; we explore this idea further in the Discussion. It should be noted here that zonal-mean jet latitude typically varies by several degrees on monthly time scales, causing monthly CRE anomalies much larger than those presented in Fig. 1. Finally, dynamics-CRE coupling may be relevant to cloud feedbacks, since the atmospheric circulation is expected to change with global warming. In the next section, we investigate the extent to which dynamical changes contribute to cloud feedbacks in climate models.

\section{Section Summary}

- Observed CRE responses to jet shifts are generally weak on zonal-mean scales.

- The SW CRE response to jet shifts is likely determined by the complex behavior of low clouds, while the LW response largely follows vertical motion anomalies.

- Changes in storm track intensity also affect clouds and radiation, but the magnitude of this effect is uncertain.

\section{Dynamical Changes with Global Warming and Cloud Feedbacks}

Due to the robust poleward shift of midlatitude jets and storm tracks seen in global warming simulations [11], it has been proposed that midlatitude storm track clouds might also shift poleward toward regions of reduced insolation [16-18], which could result in a hemispheric-mean net positive cloud feedback from the shortwave effect [17]. This idea is among the positive cloud feedback mechanisms discussed in the last Assessment Report of the Intergovernmental Panel on Climate Change [IPCC AR5, chapter 7; 1]. As discussed in the previous section, however, the SW CRE response to a jet shift is not a simple meridional dipole, being likely determined 
by the complex behavior of radiatively important low clouds, and the multi-model mean response is negligibly small in the hemispheric mean.

Focusing on the effects of SW radiation, Kay et al. [27] noted that the cloud-radiative response to jet variability is considerably smaller in magnitude than the forced response to RCP8.5 forcing in two successive versions of a climate model, CCSM4 and CESM-CAM5. Although belonging to the same family, the two versions feature very different cloud responses to jet variability, with a much larger, dipole-like response in CCSM4 [Figs. 3c and S2c in 27]. Even in CCSM4, however, the contribution of the poleward jet shift to the RCP8.5 cloud response appears to be second order. Performing a similar analysis on all available RCP8.5 experiments, Ceppi et al. [28] reached a similar conclusion (their Fig. 5). Kay et al. [27] pointed out that the RCP8.5 cloudradiative response in CESM-CAM5 reflected large changes in low cloud liquid water content, presumably driven by thermodynamic processes related to warming and boundary-layer stability changes.

Kodama et al. [29] studied the effects of warming on clouds and radiation from the perspective of individual midlatitude storms, by compositing over storms identified by a stormtracking algorithm in an aquaplanet model. Upon SST warming, they found a generalized increase in cloud liquid water at low levels, causing a substantial negative SW cloud feedback and a more modest positive LW feedback. This negative SW feedback at mid to high latitudes and the associated cloud water increases are robust features of global warming model experiments [27, 30-32]. While some of the cloud water increase was attributable to an enhancement of storm amplitude with warming, Kodama et al. [29] were unable to explain the overall cloud water increase in terms of storm intensity, suggesting it is unrelated to dynamical changes. They also concluded that the poleward shift of the storm track did not appear to significantly contribute to the SW and LW responses in their model.

We confirm and complement previous analyses by calculating the "jet-related" component of the RCP8.5 cloudradiative response for $\mathrm{SW}, \mathrm{LW}$, and net radiation (red curves and shading in Fig. 2), plotted along with the total response for comparison (black curves in Fig. 2), similar to Kay et al. [27] and Ceppi et al. [28]. The jet-related component is calculated by regression analysis of CRE onto monthly mean jet latitude [19], using the 1950-1999 period in the historical experiments of 32 CMIP5 models. The regressions are calculated for each calendar month separately, but only annual-mean results are shown. All CRE responses are adjusted to account for cloud masking effects of temperature, moisture, and surface albedo anomalies, following the radiative kernel method of Soden et al. [2]. The effect of the poleward jet shift is simply obtained by multiplying the jet-CRE regression coefficients with the jet response for each month. Because the North Atlantic and
North Pacific jets can vary independently and feature different global warming responses [11, 33, 34], the analysis is performed for each basin separately.

The SW responses feature large meridional dipoles about the midlatitudes, which are partially opposed by the LW responses. While such structures could be interpreted as resulting from a poleward expansion of the circulation, the red curves in Fig. 2 clearly show that this is not the case. It is also evident that the dynamical component is considerably smaller than the RCP8.5 anomalies for all radiation types and in all basins. The dynamical component of the CRE response in the Northern Hemisphere (NH) may be underestimated due to the zonal averaging, since the $\mathrm{NH}$ atmospheric circulation response features substantial zonal asymmetry [34]. While this may explain the smaller dynamical CRE response compared to the SH, it seems unlikely that accounting for this asymmetry would substantially affect our main conclusion. Thus, while the dynamical component of the cloud feedback can be a first-order term on a regional scale, particularly in the tropics [4], in a zonal- and annual-mean sense, the thermodynamic component appears to be dominant around the midlatitudes.

It has also been proposed that a cloud feedback could result from changes in storm track strength rather than latitude [24], since observations reveal a positive correlation between storm strength and cloudiness [7, 24]. Tselioudis and Rossow [24] anticipate an overall negative cloud feedback due to increasing storm strength, somewhat mitigated by decreasing storm frequency. However, projected storminess changes in CMIP5 are robustly positive only in the SH [35]. In addition, the results of Kodama et al. [29] suggest that the strengthening of storms explains only a small fraction of the negative cloud feedback in mid to high latitudes. Hence, while the exact magnitude of this effect remains unclear, it is most likely not a major contributor to the cloud feedback.

In summary, the results in Fig. 2, along with previous research, suggest that the meridional distribution of the changes in cloud amount, optical depth, and altitude responsible for the SW and LW global warming responses are not strongly coupled to the atmospheric circulation response, but rather associated with the thermodynamic effects of greenhouse gas forcing and its associated warming. Some implications of this result are explored in the Discussion.

\section{Section Summary}

- The poleward shift of the jet streams and storm tracks is a minor contribution to cloud feedbacks.

- Storminess changes also appear unlikely to significantly affect cloud feedbacks.

- Extratropical cloud feedbacks are mainly driven by thermodynamic processes. 
Fig. 2 CRE response to RCP8.5 forcing (thick black) and effect of poleward jet shifts (thin red, $90 \%$ intervals for the models in light red shading, observations dashed). The jet-related component of the CRE response is obtained by regressing CRE onto monthly mean jet latitude (as in Fig. 1), then multiplying the regression coefficients with the RCP8.5 jet shift for each model. The annual-mean, multi-model mean poleward jet shift is $1.7^{\circ}$ (SH), $1.3^{\circ}$ (N Atlantic), and $1.1^{\circ}$ (N Pacific), but we calculate the jet-related response for each month separately before taking annual averages. The RCP8.5 response is defined as 2050-2099 minus 1950-1999. The observations are based on CERES-EBAF CRE data [49] (March 2000February 2014) combined with ERA-Interim zonal wind [50]. The N Atlantic basin is defined as $60^{\circ} \mathrm{W}-60^{\circ} \mathrm{E}$, and the $\mathrm{N}$ Pacific as $140^{\circ} \mathrm{E}-120^{\circ} \mathrm{W}$
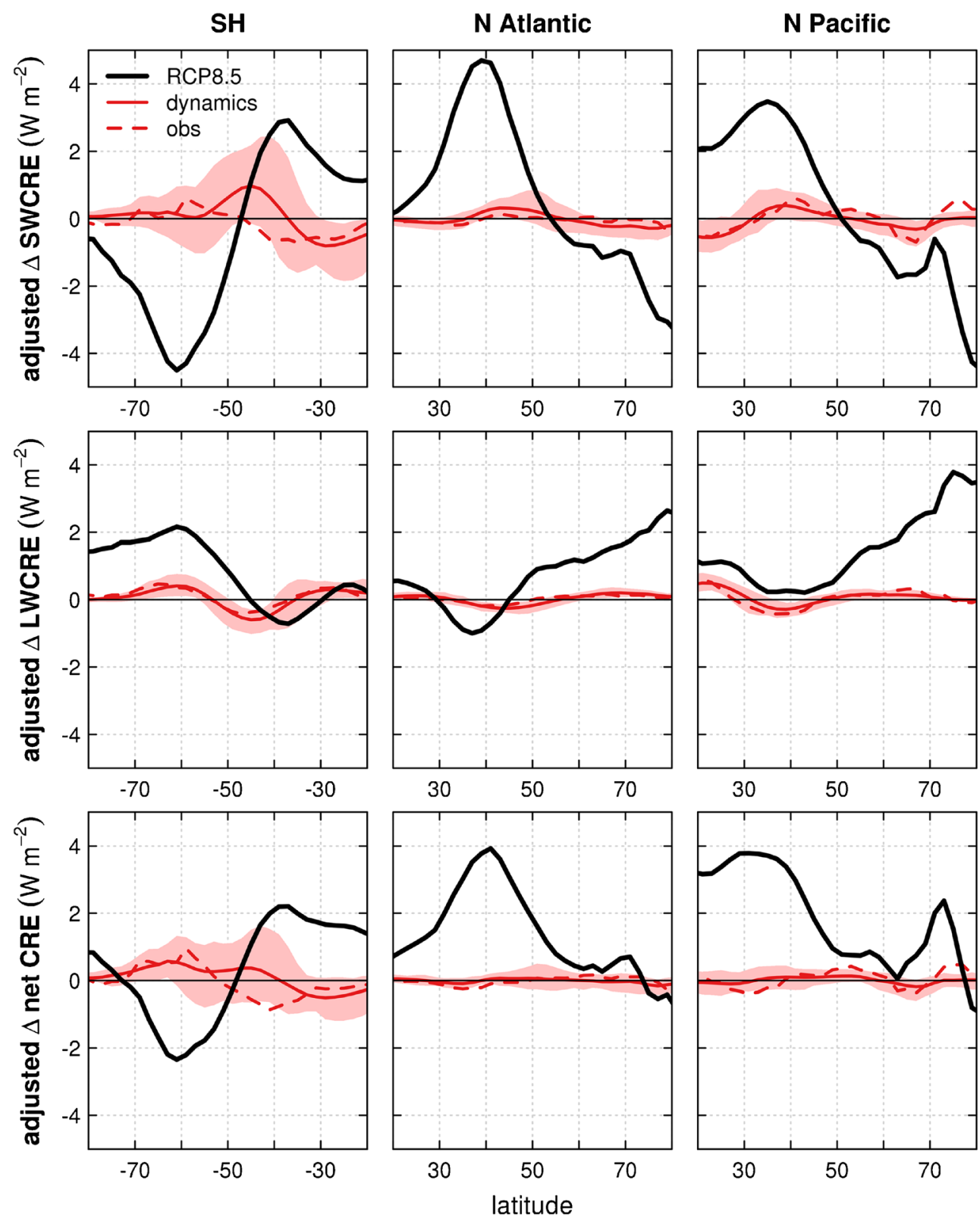

\section{Model Biases in Dynamics and in Cloud-Radiative Effects}

We now briefly examine the effect of dynamical biases on the representation of clouds and radiation in climate models. It is of interest to determine whether model biases in CRE occur due to a wrong representation of dynamics or because the models are unable to correctly depict the mean CRE for a given dynamical state. To address this question, a number of studies have analyzed the dependence of clouds and radiation on extratropical dynamics, with special focus on midlatitude storms $[6,21,23,36,37]$. This question is of particular interest in the Southern midlatitudes, where a majority of CMIP5 models tend to underestimate the amount of reflected shortwave radiation $[6,22,36]$.

Govekar et al. [21] compared the representation of midlatitude cyclones in observations with the ACCESS climate model and found that part of the CRE bias was caused by an underestimation of the strength of storms, associated with an underrepresentation of cloud fraction. However, the model was also unable to accurately reproduce observed relationships between cloud fraction, vertical motion, and relative humidity, suggesting that part of the model CRE biases is unrelated to dynamical biases.

Studies have also linked CRE biases over the Southern midlatitudes to a systematic underestimation of cloudiness in 
the cold sector of storms, particularly linked to low- and midlevel clouds [6, 21, 36, 38]. Williams et al. [36] ascribed this bias to insufficient vertical resolution of the boundary layer, which affects the boundary layer depth. They also noted that models run in hindcast mode (initialized from reanalyses) develop model-specific CRE biases within a very short time frame, mainly in the first 24 to $48 \mathrm{~h}$ after initialization, when the dynamics are still very close to the reanalysis. Similarly, Ma et al. [37] found that CMIP5 models run in hindcast mode rapidly develop forecast errors similar to their climate biases, which they ascribed to the model physics (including cloud parameterizations). Taken together, these results strongly suggest that the CRE biases are not caused by dynamical biases, but rather by physical parameterizations and model resolution.

\section{Section Summary}

- Model biases in clouds and radiation are due to model physics, not to biases in dynamics.

- CRE biases have been linked to insufficient low- and midlevel cloudiness in the cold sector of storms.

\section{Discussion}

Understanding and constraining cloud feedbacks is one of the most pressing problems in current climate research. The most recent generation of state-of-the-art climate models still suffers from large uncertainty in the cloud-radiative response to global warming, which affects climate sensitivity estimates $[1,3,39]$. From this perspective, one important implication of the results above is that constraining the circulation response to global warming may not significantly reduce the uncertainty in the extratropical cloud feedback. This underlines the importance of studying the thermodynamic processes relevant to the cloud response. Around the midlatitudes, changes in optical depth associated with the amount of cloud liquid water appear to be particularly relevant to the cloud feedback, driven by the SW effect of low clouds [27, 31, 32, $39,40]$. Further research is necessary to understand how the cloud liquid water response to climate change depends on processes such as changes in boundary layer properties, phase changes in mixed-phase clouds, increases in moisture availability with warming, and aerosol forcing. Understanding the effects of such processes may also help identify observational constraints on the climate change response.

In this review paper, we have mainly discussed how dynamical changes affect clouds and radiation. However, there is increasing evidence that cloud-radiative effects can also feed back onto the atmospheric circulation, by regulating spatial patterns of diabatic heating. We believe that the most pressing open question in the field of cloud-midlatitude dynamics interactions concerns the extent to which clouds and radiation can affect the atmospheric circulation. It has been shown that cloud-radiative biases affect the general structure of the circulation (Y. Li et al., The influence of cloud radiative effects on the large-scale atmospheric circulation, paper submitted to Journal of Climate), and CRE biases appear to explain part of the circulation biases in climate models [41, 42]. Additional research is needed to address the following two questions:

1. To what extent can cloud-radiative effects dampen or amplify atmospheric modes of variability?

We have shown that the dominant mode of extratropical dynamical variability, consisting of a meridional shift of the midlatitude jet, yields relatively small changes in CRE on annual- and zonal-mean scales. Nevertheless, the possible importance of such seemingly small CRE variability remains to be assessed. For example, Li et al. [20] point out that the LW anomalies associated with the NAM tend to dampen the temperature anomalies during winter, which could reduce the persistence of the annular mode. In addition, SW anomalies could affect the magnitude of SST anomalies driven by dynamical variability, affecting ocean-atmosphere coupling time scales. To our knowledge, the impact of cloud-radiative anomalies on the persistence of dynamical modes of variability has not been quantified. Such an effect would likely be seasonally dependent, since the relative magnitude of the SW and LW effects is a strong function of the season.

2. To what extent can cloud feedbacks modulate the atmospheric circulation response?

The current generation of climate models suffers from large uncertainty in the representation of the extratropical circulation response to climate change [e.g., 11, 43]. While a substantial fraction of this uncertainty is related to dynamical biases [44], there is increasing evidence that cloud processes also contribute to the spread in the dynamical response. For example, the meridional structure of SW cloud feedbacks has been related to inter-model differences in the jet response [28] and in ITCZ shifts [45] through differences in the spatial patterns of warming. The multi-model mean SW cloud feedback in the RCP8.5 experiment of CMIP5 consists of a meridional dipole with enhanced subtropical warming and a negative feedback at high latitudes, which tends to enhance the equator-to-pole temperature gradient; such a response could contribute to the poleward shift of the midlatitude jet and storm track $[28,46]$. Using a cloud-locking procedure in two climate models, Voigt and Shaw [47] showed that LW cloud feedbacks also tend to enhance the poleward shift of the midlatitude jets upon an SST increase; they ascribed this result to the stabilization of the tropical troposphere by the LW cloud feedback, which acts to shift the baroclinically unstable regions poleward. 
This implies that constraining cloud feedbacks is important not only in terms of climate sensitivity but also because the diabatic forcing patterns associated with clouds likely contribute to the dynamical sensitivity to global warming [48]. Thus, future research should investigate how SW and LW cloud feedbacks separately contribute to the dynamical response and how much of the inter-model spread in the circulation response can be ascribed to uncertainty in cloud feedbacks.

\section{Conclusions}

This study reviews our understanding of interactions between midlatitude dynamics, clouds, and their associated radiative effects, with a focus on large-scale climate implications. We summarize our review in terms of the three questions defined in the introduction:

1. How do the dominant modes of dynamical variability affect clouds and radiation?

Jet variability has a small but non-negligible effect on SW and LW CRE on zonal-mean scales. The observed SW radiation response does not reflect a simple poleward shift of the clouds, and models disagree on the representation of this effect. Results suggest that the SW CRE response may be governed by the behavior of low-level clouds, whose representation is problematic in models. In contrast, the LW CRE response to jet shifts reflects a simple meridional shift of the radiatively relevant mid- to high-level clouds, following vertical motion anomalies. This response is robust and well represented in climate models. In addition to jet shifts, storm intensity changes also impact CRE, but the importance of this effect for CRE variability remains to be assessed. The possible relevance of cloud-dynamics coupling to the persistence of modes of dynamical variability is a topic of future research.

2. Does the dynamical response to global warming affect cloud feedbacks?

The dynamical response to global warming in midlatitudes is dominated by a poleward jet shift. However, this effect appears to explain only a modest fraction of the cloud feedback in climate models. While the impact of storminess changes has not been accurately quantified, this is likely a second-order effect for clouds and radiation. We conclude that thermodynamic effects on cloud amount, optical depth, and altitude must control the cloud response to global warming around the midlatitudes.

3. Do model biases in dynamics cause biases in clouds and radiation?

Cloud-radiative biases occur in climate model simulations that are nudged to the reanalysis, in which dynamical biases are minimal. In addition, when compared to observations, models are unable to correctly simulate cloud properties for particular dynamic and thermodynamic states. This indicates that cloud-radiative biases are primarily linked to parameterized physics rather than dynamical biases. In addition to the cloud schemes, vertical resolution in the boundary layer has been shown to be important for low clouds.

We conclude by highlighting the two future research directions that we see as most important with regard to this review: (a) understanding the impact of cloud feedbacks on the atmospheric circulation response to climate change and (b) identifying and understanding the thermodynamic (non-dynamics related) processes that control extratropical cloud feedbacks. Progress on these issues will be necessary to reduce uncertainty in climate sensitivity estimates and constrain the atmospheric circulation response to global warming.

Acknowledgments We wish to acknowledge Robert Wood for helpful discussions, as well as Kevin Grise and two anonymous reviewers for their comments. This work was supported by the National Science Foundation under grant AGS-0960497.

\section{Compliance with Ethics Guidelines}

Conflict of Interest On behalf of all authors, the corresponding author states that there is no conflict of interest.

Human and Animal Rights and Informed Consent This article does not contain any studies with human or animal subjects performed by any of the authors.

\section{References}

1. Boucher O, Randall D, Artaxo P, et al. Clouds and aerosols. In: Stocker TF, Qin D, Plattner G-K, et al., editors. Climate Change 2013: The Physical Science Basis. Cambridge: Cambridge University Press; 2013. p. 571-657.

2. Soden BJ, Held IM, Colman R, et al. Quantifying climate feedbacks using radiative kernels. J Clim. 2008;21:3504-20. doi:10.1175/ 2007JCLI2110.1.

3. Vial J, Dufresne J-L, Bony S. On the interpretation of inter-model spread in CMIP5 climate sensitivity estimates. Clim Dyn. 2013;41: 3339-62. doi:10.1007/s00382-013-1725-9.

4. Bony S, Dufresne J-L, Le Treut H, et al. On dynamic and thermodynamic components of cloud changes. Clim Dyn. 2004;22:71-86. doi:10.1007/s00382-003-0369-6.

5. Field PR, Bodas-Salcedo A, Brooks ME. Using model analysis and satellite data to assess cloud and precipitation in midlatitude cyclones. Q J R Meteorol Soc. 2011;137:1501-15. doi:10.1002/qj. 858.

6. Bodas-Salcedo A, Williams KD, Ringer MA, et al. Origins of the solar radiation biases over the Southern Ocean in CFMIP2 models. J Clim. 2014;27:41-56. doi:10.1175/JCLI-D-13-00169.1 .

7. Li Y, Thompson DWJ, Stephens GL, Bony S. A global survey of the instantaneous linkages between cloud vertical structure and 
large-scale climate. J Geophys Res Atmos. 2014;119:3770-92. doi: 10.1002/2013JD020669.

8. Alexander MA, Lau N-C, Scott JD. Broadening the atmospheric bridge paradigm: ENSO teleconnections to the tropical west Pacific-Indian oceans over the seasonal cycle and to the north Pacific in summer. In: Earth's Climate: The Ocean-Atmosphere Interaction. American Geophysical Union; 2004. doi:10.1029/ GM147.

9. Park S, Alexander MA, Deser C. The impact of cloud radiative feedback, remote ENSO forcing, and entrainment on the persistence of north Pacific Sea surface temperature anomalies. J Clim. 2006;19:6243-61. doi:10.1175/JCLI3957.1.

10. Yin JH. A consistent poleward shift of the storm tracks in simulations of 21st century climate. Geophys Res Lett. 2005;32, L18701. doi:10.1029/2005GL023684.

11. Barnes EA, Polvani L. Response of the midlatitude jets and of their variability to increased greenhouse gases in the CMIP5 models. J Clim. 2013;26:7117-35. doi:10.1175/JCLI-D-12-00536.1.

12. Thompson DWJ, Wallace JM. Annular modes in the extratropical circulation. Part I: month-to-month variability. J Clim. 2000;13: 1000-16. doi:10.1175/1520-0442(2000)013<1000:AMITEC $>2.0$. $\mathrm{CO} ; 2$.

13. Thompson DW, Wallace JM. Regional climate impacts of the Northern Hemisphere annular mode. Science. 2001;293:85-9. doi:10.1126/science.1058958.

14. Limpasuvan V, Hartmann DL. Wave-maintained annular modes of climate variability. J Clim. 2000;13:4414-29. doi:10.1175/15200442(2000)013<4414:WMAMOC >2.0.CO;2.

15. Hall A, Visbeck M. Synchronous variability in the Southern Hemisphere atmosphere, sea ice, and ocean resulting from the annular mode. J Clim. 2002;15:3043-57. doi:10.1175/15200442(2002)015<3043:SVITSH $>2.0 . \mathrm{CO} ; 2$.

16. Bender FA-M, Ramanathan V, Tselioudis G. Changes in extratropical storm track cloudiness 1983-2008: observational support for a poleward shift. Clim Dyn. 2012;38:2037-53. doi:10. 1007/s00382-011-1065-6.

17. Grise KM, Polvani LM, Tselioudis G, et al. The ozone hole indirect effect: cloud-radiative anomalies accompanying the poleward shift of the eddy-driven jet in the Southern Hemisphere. Geophys Res Lett. 2013;40:3688-92. doi:10.1002/grl.50675.

18. Eastman R, Warren SG. A 39-yr survey of cloud changes from land stations worldwide 1971-2009: long-term trends, relation to aerosols, and expansion of the tropical belt. J Clim. 2013;26:1286-303. doi:10.1175/JCLI-D-12-00280.1.

19. Grise KM, Polvani LM. Southern Hemisphere cloud-dynamics biases in CMIP5 models and their implications for climate projections. J Clim. 2014;27:6074-92. doi:10.1175/JCLI-D-14-00113.1.

20. Li Y, Thompson DWJ, Huang Y, Zhang M. Observed linkages between the northern annular mode/North Atlantic oscillation, cloud incidence, and cloud radiative forcing. Geophys Res Lett. 2014;41:1681-8. doi:10.1002/2013GL059113.

21. Govekar PD, Jakob C, Catto J. The relationship between clouds and dynamics in Southern Hemisphere extratropical cyclones in the real world and a climate model. J Geophys Res Atmos. 2014;119:660928. doi:10.1002/2013JD020699.

22. Bodas-Salcedo A, Williams KD, Field PR, Lock AP. The surface downwelling solar radiation surplus over the Southern Ocean in the Met Office Model: the role of midlatitude cyclone clouds. J Clim. 2012;25:7467-86. doi:10.1175/JCLI-D-11-00702.1.

23. Govekar PD, Jakob C, Reeder MJ, Haynes J. The threedimensional distribution of clouds around Southern Hemisphere extratropical cyclones. Geophys Res Lett. 2011;38:n/a-n/a. doi: 10.1029/2011GL049091.

24. Tselioudis G, Rossow WB. Climate feedback implied by observed radiation and precipitation changes with midlatitude storm strength and frequency. Geophys Res Lett. 2006;33:L02704. doi:10.1029/ 2005GL024513.

25. Thompson DWJ, Woodworth JD. Barotropic and baroclinic annular variability in the Southern Hemisphere. J Atmos Sci. 2014;71: 1480-93. doi:10.1175/JAS-D-13-0185.1.

26. Thompson DWJ, Li Y. Baroclinic and barotropic annular variability in the Northern Hemisphere. J Atmos Sci. 2014;141009113140004. doi: 10.1175/JAS-D-14-0104.1.

27. Kay JE, Medeiros B, Hwang Y-T, et al. Processes controlling Southern Ocean shortwave climate feedbacks in CESM. Geophys Res Lett. 2014;41:616-22. doi:10.1002/2013GL058315.

28. Ceppi P, Zelinka MD, Hartmann DL. The response of the Southern Hemispheric eddy-driven jet to future changes in shortwave radiation in CMIP5. Geophys Res Lett. 2014;41:3244-50. doi:10.1002/ 2014GL060043.

29. Kodama C, Iga S, Satoh M. Impact of the sea surface temperature rise on storm-track clouds in global nonhydrostatic aqua planet simulations. Geophys Res Lett. 2014;41:3545-52. doi:10.1002/ 2014 GL059972.

30. Zelinka MD, Klein SA, Hartmann DL. Computing and partitioning cloud feedbacks using cloud property histograms. Part II: attribution to changes in cloud amount, altitude, and optical depth. J Clim. 2012;25:3736-54. doi:10.1175/JCLI-D-11-00249.1.

31. Gordon ND, Klein SA. Low-cloud optical depth feedback in climate models. J Geophys Res Atmos. 2014;119:6052-65. doi:10. 1002/2013JD021052.

32. McCoy DT, Hartmann DL, Grosvenor DP. Observed southern ocean cloud properties and shortwave reflection part 2: phase changes and low cloud feedback. J Clim. 2014;141006071055006. doi: 10.1175/JCLI-D-14-00288.1

33. Wettstein JJ, Wallace JM. Observed patterns of month-to-month storm-track variability and their relationship to the background flow. J Atmos Sci. 2010;67:1420-37. doi:10.1175/2009JAS3194.1.

34. Simpson IR, Shaw TA, Seager R. A diagnosis of the seasonally and longitudinally varying midlatitude circulation response to global warming. J Atmos Sci. 2014;71:2489-515. doi:10.1175/JAS-D13-0325.1.

35. Chang EKM, Guo Y, Xia X. CMIP5 multimodel ensemble projection of storm track change under global warming. J Geophys Res. 2012;117:D23118. doi:10.1029/2012JD018578.

36. Williams KD, Bodas-Salcedo A, Déqué M, et al. The transposeAMIP II experiment and its application to the understanding of Southern Ocean cloud biases in climate models. J Clim. 2013;26: 3258-74. doi:10.1175/JCLI-D-12-00429.1.

37. Ma H-Y, Xie S, Klein SA, et al. On the correspondence between mean forecast errors and climate errors in CMIP5 models. J Clim. 2014;27:1781-98. doi:10.1175/JCLI-D-13-00474.1.

38. Mason S, Jakob C, Protat A, Delanoë J. Characterizing observed midtopped cloud regimes associated with Southern Ocean shortwave radiation biases. J Clim. 2014;27:6189-203. doi:10.1175/ JCLI-D-14-00139.1.

39. Zelinka MD, Klein SA, Taylor KE, et al. Contributions of different cloud types to feedbacks and rapid adjustments in CMIP5*. J Clim. 2013;26:5007-27. doi:10.1175/JCLI-D-12-00555.1.

40. Tsushima Y, Emori S, Ogura T, et al. Importance of the mixedphase cloud distribution in the control climate for assessing the response of clouds to carbon dioxide increase: a multi-model study. Clim Dyn. 2006;27:113-26. doi:10.1007/s00382-006-0127-7.

41. Ceppi P, Hwang Y-T, Frierson DMW, Hartmann DL. Southern Hemisphere jet latitude biases in CMIP5 models linked to shortwave cloud forcing. Geophys Res Lett. 2012;39, L19708. doi:10. 1029/2012GL053115.

42. Hwang Y-T, Frierson DMW. Link between the double-intertropical convergence zone problem and cloud biases over the southern ocean. Proc Natl Acad Sci U S A. 2013;110:4935-40. doi:10. 1073/pnas.1213302110. 
43. Shepherd TG. Atmospheric circulation as a source of uncertainty in climate change projections. Nat Geosci. 2014;7:703-8. doi:10. 1038/ngeo2253.

44. Kidston J, Gerber EP. Intermodel variability of the poleward shift of the austral jet stream in the CMIP3 integrations linked to biases in 20th century climatology. Geophys Res Lett. 2010;37:L09708. doi: 10.1029/2010GL042873.

45. Frierson DMW, Hwang Y-T. Extratropical influence on ITCZ shifts in slab ocean simulations of global warming. J Clim. 2012;25:72033. doi:10.1175/JCLI-D-11-00116.1.

46. Harvey BJ, Shaffrey LC, Woollings TJ. Equator-to-pole temperature differences and the extra-tropical storm track responses of the CMIP5 climate models. Clim Dyn. 2013. doi:10.1007/s00382-013-1883-9.
47. Voigt A, Shaw TA. Circulation response to warming shaped by radiative changes of clouds and water vapour. Nat Geosci. 2015. doi:10.1038/ngeo2345.

48. Grise KM, Polvani LM. Is climate sensitivity related to dynamical sensitivity? A Southern Hemisphere perspective. Geophys Res Lett. 2013. doi:10.1002/2013GL058466.

49. Wielicki BA, Barkstrom BR, Harrison EF, et al. Clouds and the Earth's Radiant Energy System (CERES): an earth observing system experiment. Bull Am Meteorol Soc. 1996;77:853-68. doi:10. 1175/1520-0477(1996)077<0853:CATERE $>2.0 . C O ; 2$.

50. Dee DP, Uppala SM, Simmons AJ, et al. The ERA-Interim reanalysis: configuration and performance of the data assimilation system. Q J R Meteorol Soc. 2011;137:553-97. doi:10.1002/qj.828. 